\title{
Assessment of Palatal Height Index and palatal form in different malocclusions in adult patients visiting Nishtar Institute of Dentistry, Multan
}

\author{
Dr. Asia Khalid', Dr. Faisal Rasheed², Dr. Zubair H. Awaisi ${ }^{3}$ \\ 'BDS, PGR, ${ }^{2} \mathrm{BDS}, \mathrm{PGR},{ }^{3} \mathrm{BDS}, \mathrm{FCPS}, \mathrm{HOD}$ Orthodontics, \\ Nishtar Institute of Dentistry, Multan.
}

Corresponding author: Dr. Asia Khalid; Email: asiadr01@gmail.com

\section{ABSTRACT}

Introduction: This study was conducted to evaluate the palatal height index in different malocclusion because of appearance of variable palatal heights \& palatal forms

Materials \& Method: In this study 108 adult subjects (41 males, 67 females), age ranges from 13-28yrs, were randomly selected from Orthodontic Department In Nishtar Institute of Dentistry Multan. Their impressions were taken by the Alginate and dental casts were formed and lateral cephalograms were collected. One sample $t$ test was used to calculate the results.

Result: Descriptive statistics showed mean palatal index of $60.95 \%$ in skeletal class I, $48.31 \%$ in skeletal class II, whereas $61.26 \%$ in skeletal class III. Frequency distribution in different skeletal patterns showed $100 \%$ high palate in class I and class III whereas skeletal class II showed variety in palatal form with $82.3 \%$ high palate, $11.3 \%$ medium palate and remaining $6.3 \%$ was low palate. major portion of the sample had high palate.

Conclusion: Mean index in Skeletal Class I is $60.95 \%, 48.31 \%$ in skeletal class II, $61.26 \%$ in skeletal class III. Mean palatal height index in females is significantly higher than in males. Skeletal class II has variety of palatal form with high prevalence of high palate. Most common palatal form is high palate.

KEYWORDS: Palatal height index, Skeletal class I,II,III pattern

\section{INTRODUCTION}

Every individual is born with his unique craniofacial structural relations, craniofacial formulations \& individual facial characteristics which are different from the rest of the people in the world. The palatal arch form and the palatal dimensions play a key role in assessing the facial form of a particular person and helps a lot in diagnosing if there is any orthodontic problem. ${ }^{1} \mathrm{~A}$ generalized overview of anatomy of palate narrates that palate is the anatomical structure which is mainly composed of two components.i.e Hard palate, that is bony structure that incorporates dentition and Soft palate which is neuromuscular organ. In comparison of two components, the hard palate is supposed to be more vital structure that is associated with the speech function. If there occurs any disturbance in the formation of palate that leads to a malformation called as cleft palate and the associated problems are like difficulty in speech, narrow palatal width, narrow maxillary arch. ${ }^{3} \mathrm{~A}$ high or narrow palate is an indicator of syndromic situations .eg .Turners syndrome, Aperts syndrome, Treacher collin syndrome, Trisomy 21 syndrome and others. ${ }^{6}$ Due to appearance of variability in the shape of palatal vaults in each skeletal pattern we decided to conduct this study to investigate the palatal vault morphology in different malocclusions i.e. skeletal class $\mathrm{I}, \mathrm{II}, \mathrm{III}$ and to determine gender differences in adult patients coming to Orthodontics Department in Nishtar Institute of Dentistry Multan.

\section{MATERIALS AND METHODS}

The study was conducted in Nishtar Institue of Dentistry 
Multan for 4 months from Dec,2019 to March, 2020. The size of sample was 108 randomly selected outdoor adult patients, age ranges from $13 y$ rs to $28 y$ rs. The lateral cephalograms and alginate impressions were taken. The dental casts were formed with dental stones and the cephalometric tracing was done on Acetate Matte sheets. Dental casts were selected fulfilling the following requirements:

1. First molars present.

2. Complete erupted canines

3. Casts with no bubbles, voids and repair.

The subjects were categorized on basis of ANB angle into Skeletal class I, II, III patterns. The palatal height and width were measured on the cast with reference to particular points. The shortest distance between midline at the junction of hard palate and soft palate and the horizontal plane established by the molar points is the palatal height. The distance between the maxillary molars at the cervical line was the palatal width. All the measurements were taken in millimeters. Index was calculated by the following formula

Height/Width X100

On the basis of following formula, the study conducted by Maria $\mathrm{CM}, 7$ the depth of palate was categorized in 3 classes:
a. $\leq 27.9 \% \quad$ (Low palate)
b. $28.0-39.9 \%$ (Medium palate)
c. $\geq 40 \% \quad$ (High palate)

The data was analyzed by using SPSS statistical software.

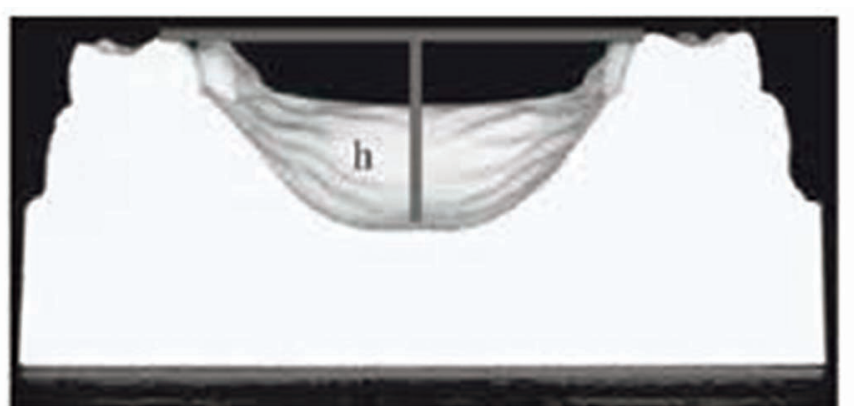

Figure 1 Palatal Height \& width

\section{RESULTS}

This study comprised of 108 adult subjects in which 41 males and 67 females participated. The descriptive statistics showed mean palatal index of $60.95 \%$ in skeletal class I, $48.31 \%$ in skeletal class II, whereas $61.26 \%$ in skeletal class III. Mean palatal width and height in skeletal class I are $27.14 \mathrm{~mm}$ and $20.84 \mathrm{~mm}$ respectively. Mean palatal width and height are $33.9 \mathrm{~mm}$ and $16.29 \mathrm{~mm}$ in skeletal classII and in skeletal class III they are $28.22 \mathrm{~mm}$ and $21.56 \mathrm{~mm}$ respectively as shown in table 1.

Frequency distribution in different skeletal patterns showed $100 \%$ high palate in class I and class III whereas skeletal class II showed variety in palatal form with $82.3 \%$ high palate, $11.3 \%$ medium palate and remaining $6.3 \%$ was low palate.

Table 1. Mean Age, P.Width, P.Height index according to Skeletal class

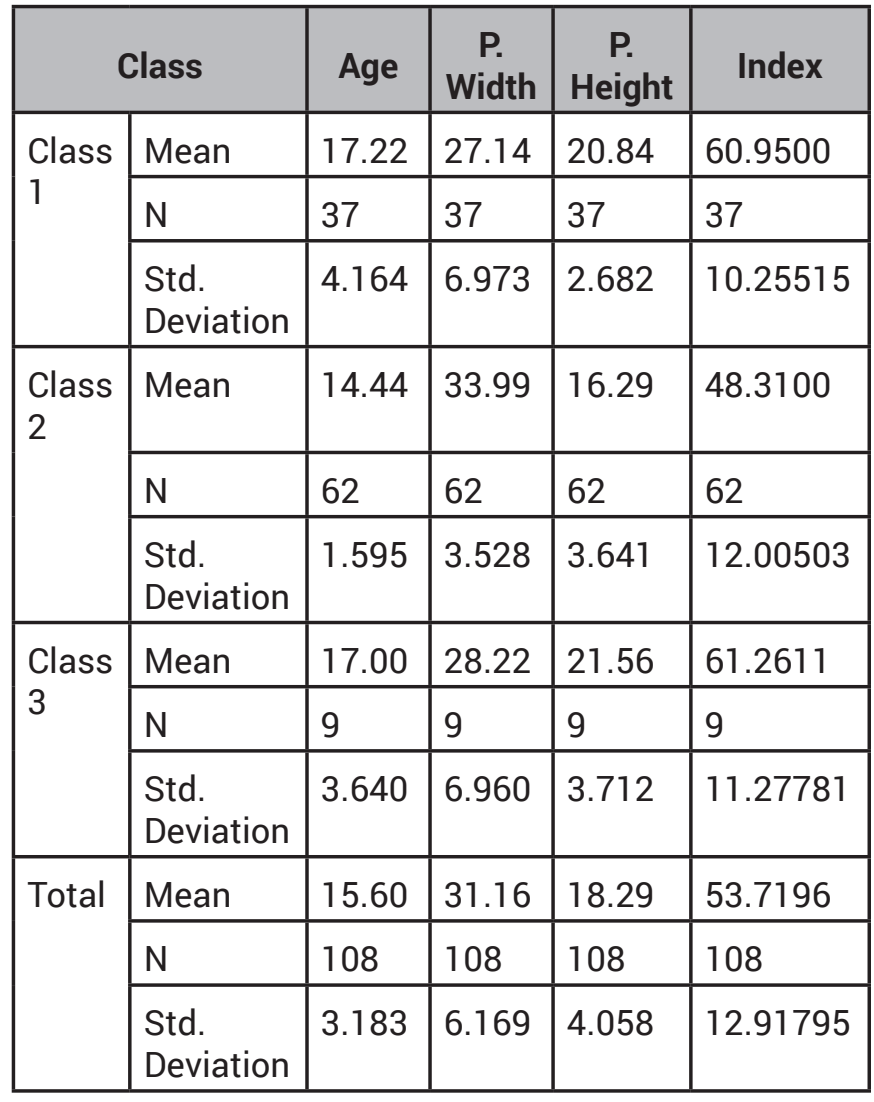

The low palate cases( index of $\leq 27.9 \%$ ) had mean index of $23.36 \%$,medium palate(index of $28-39.9 \%$ ) had mean index of $33.85 \%$ and mean index of high palate (index of $\geq 40$ ) was $56.64 \%$. Out of 108 subjects, $96(88 \%)$ were found to have high palate, $8(7.4 \%)$ were with medium palate and remaining $4(3.7 \%)$ with low palate as shown in table 2. The average index in males was $51.12 \%$ indicating high palate and female subjects were also found to be having index of $55.30 \%$ indicating high palate. Overall mean index was $53.71 \%$ indicating major portion of the sample had high palate according to table 3. 
Table 2. Mean Age P.Width P.Height index according to Palate forms

\begin{tabular}{|l|l|l|l|l|l|}
\hline \multicolumn{2}{|c}{} & Age & P.Width & P.Height & Index \\
\hline \multirow{4}{*}{ Low palate $\leq 27.9 \%$} & Mean & 14.75 & 34.50 & 8.00 & 23.3600 \\
\cline { 2 - 6 } & $\mathrm{N}$ & 4 & 4 & 4 & 4 \\
\cline { 2 - 6 } & Std. Deviation & .500 & 4.655 & .816 & 2.42447 \\
\hline \multirow{5}{*}{ Medium palate 28-39.9\% } & Mean & 14.13 & 36.31 & 12.25 & 33.8525 \\
\cline { 2 - 6 } & $\mathrm{N}$ & 8 & 8 & 8 & 8 \\
\cline { 2 - 6 } & Std. Deviation & .641 & 4.432 & 1.832 & 3.77355 \\
\hline \multirow{5}{*}{ High palate $\geq 40 \%$} & Mean & 15.76 & 30.59 & 19.22 & 56.6402 \\
\cline { 2 - 6 } & N & 96 & 96 & 96 & 96 \\
\cline { 2 - 6 } & Std. Deviation & 3.336 & 6.140 & 3.143 & 10.29811 \\
\hline \multirow{5}{*}{ Total } & Mean & 15.60 & 31.16 & 18.29 & 53.7196 \\
\cline { 2 - 6 } & N & 108 & 108 & 108 & 108 \\
\cline { 2 - 6 } & Std. Deviation & 3.183 & 6.169 & 4.058 & 12.91795 \\
\hline
\end{tabular}

The results of $t$ test are shown in table 5 . Keeping the $p$ value as 0.05 statistically insignificant results.

Table 3. Age P.Width P.Height index according to Gender

\begin{tabular}{|c|c|c|c|c|c|}
\hline & Gender & Age & P.Width & P.Height & index \\
\hline \multirow[t]{3}{*}{ Male } & Mean & 15.66 & 32.70 & 18.07 & 51.1210 \\
\hline & $N$ & 41 & 41 & 41 & 41 \\
\hline & Std. Deviation & 3.381 & 6.581 & 4.886 & 14.47405 \\
\hline \multirow[t]{3}{*}{ Female } & Mean & 15.57 & 30.22 & 18.42 & 55.3099 \\
\hline & $N$ & 67 & 67 & 67 & 67 \\
\hline & Std. Deviation & 3.081 & 5.752 & 3.491 & 11.69644 \\
\hline \multirow[t]{3}{*}{ Total } & Mean & 15.60 & 31.16 & 18.29 & 53.7196 \\
\hline & $N$ & 108 & 108 & 108 & 108 \\
\hline & Std. Deviation & 3.183 & 6.169 & 4.058 & 12.91795 \\
\hline
\end{tabular}

Table 4. One-Sample Statistics

\begin{tabular}{|l|l|l|l|l|}
\hline & N & Mean & Std. Deviation & Std. Error Mean \\
\hline index & 108 & 53.7196 & 12.91795 & 1.24303 \\
\hline
\end{tabular}

Table 4. One-Sample Test

\begin{tabular}{|l|l|l|l|l|l|l|}
\hline & \multicolumn{5}{|c|}{ Test Value = 53.71 } \\
\cline { 2 - 7 } & $\mathbf{t}$ & $\mathrm{df}$ & Sig. (2-tailed) & Mean Difference & \multicolumn{2}{|l|}{ 95\% Confidence Interval of the Difference } \\
\cline { 5 - 7 } & & & & & Lower & Upper \\
\hline index & .008 & 107 & .994 & .00963 & -2.4545 & 2.4738 \\
\hline
\end{tabular}




\section{DISCUSSION}

Upcoming changes due to different treatment modalities are different for every individual because of his/her morphology so it is essential to understand every individual patient by defining his/her basic skeletal and dental structure to decide effective treatment mechanics for his/her malocclusion.

In this study, descriptive statistics showed mean palatal index of $60.95 \%$ in skeletal class I, $48.31 \%$ in skeletal class II, whereas $61.26 \%$ in skeletal class III. Mean palatal width and height in skeletal class I are $27.14 \mathrm{~mm}$ and $20.84 \mathrm{~mm}$ respectively. Mean palatal width and height are $33.9 \mathrm{~mm}$ and $16.29 \mathrm{~mm}$ in skeletal classII and in skeletal class III they are $28.22 \mathrm{~mm}$ and $21.56 \mathrm{~mm}$ respectively.

In 1970, Linder Aronson declared abnormal palatal height in mouth breathers. ${ }^{17}$ In 1952, Ballard and Gwynne conducted 15 years study, mentioned that adenoid patients have high palates. ${ }^{18}$ In 1971 , Klein said that if finger sucking persist in children after two years of age might causes dome palate abnormality. ${ }^{19}$ In 1965 Cleall and Brossman in 1972 stated that disorders of maxillar growth are important in width, depth and height. ${ }^{20,21}$ In a study of 47 children and 47 adults conducted by Handelman in 2000, it was illustrated that palatal height increased by $18 \%$ in adults and $56 \%$ in children. ${ }^{22}$ In 1934 Ashley Montagu developed "Palatal Index" to assess relative palatal height. ${ }^{23}$

Palatal height index values explained by other writers may differ from the material examined. There may be physical differences between Australian and U.S. population but different points may also explain variation in findings. Redman et al. ${ }^{24}$ in order to avoid palatine tori, measured palatal height at junction of hard and soft palates. As this is not the deepest part of the palate, result was smaller palatal height values.

In our study, out of 108 subjects, $88 \%$ were found to have high palate, $7.4 \%$ were with medium palate and remaining $3.7 \%$ with low palate.
Different populations, ethnic backgrounds and races tend to have different palatal form and depth. According to Nurul Afiqah1 palatal height index of two populations, Malaysian and Indian were comapared and the results showed $50 \%$ of Indian population and $67 \%$ of Malaysian population showed low palate, $33 \%$ of Indian and $20 \%$ of Malaysian Population showed medium type palate, $20 \%$ Indian and $13 \%$ Malaysian population showed high palate.

\section{CONCLUSION}

This study concludes with the following observations:

1. Mean index in Skeletal Class I is $60.95 \%, 48.31 \%$ in skeletal class II, $61.26 \%$ in skeletal class III.

2. Mean palatal height index in females is significantly higher than in males.

3. Skeletal class II has variety of palatal form with high prevalence of high palate.

4. Most common palatal form is high palate. 


\section{REFERENCES}

1. Al-Quadaimi NH, Ali Fa,Made AA,Al-Sanabani FA.Palatal depth in normal occlusionin class -I with dental crowding for agroup of Yemini school children. Austin Dent Sci2016;1:1005

2. Mankapure, P.K., Barpande, S.R. and Bhavthankar, J.D., 2017. Evaluation of sexual dimorphism in arch depth and palatal depth in 500 young adults of Marathwada region, India. Journal of forensic dental sciences, 9(3), p.153.

3. Nurul Afiqah Amani Binti Zaaba, Ashish R Jain.Association between the maxillary arch form and length,width,,and depth of palate in Malaysian and Indian Population. Drug intervention today 2018;10:5

4. Das, S., Gupta, T., Dholam, K., Chouksey, G., Laskar, S. G., \& Agarwal, J. P. (2015). Is palatal vault height a determinant for nasopharyngeal carcinoma: A hypothesis?. Medical hypotheses, 85(5), 534-536.

5. Ahmad HM, Al-Khawajah NF,Nahidh M.Assessementof palatal dimensions in a sample of Iraqi adults with different facial forms. Iraqi Orthod J 2014;10:8-11

6. Redman, R. S., Shapiro, B. L., \& Gorlin, R. J. (1966). Measurement of normal and reportedly malformed palatal vaults. II. Normal juvenile measurements. Journal of dental research, 45(2), 266-269.

7. Maria CM, Silva AM, Busanello-Stella AR, Bolzan GP, Berwig LC. Avaliação da profundidade do palate duro: Correlação entre método quantitative e qualitative. Rev CEFAC 2013;15:1292-9

8. M.Zarringham.Measuring palatal Height in Normal Occlusion and Malocclusions.J Dent,Tehran University Medic Sci 2004;1(4):39-42.

9. Howell S. Assessment of palatal height in children. Community dentistry and oral epidemiology. 1981 Feb;9(1):44-7.

10. Hassanali J, Mwaniki D. Palatal analysis and osteology of the hard palate of the Kenyan African skulls. The Anatomical Record. 1984 Jun;209(2):273-80.

11. Amirabadi GE, Golshah A, Derakhshan S, Khandan S, Saeidipour M, Nikkerdar N. Palatal dimensions at different stages of dentition in 5 to 18-year-old Iranian children and adolescent with normal occlusion. BMC oral health. 2018 Dec;18(1):87.

12. Manjula WS, Murali RV, Kumar SK, with Down syndrome-a comparative study. Down Syndrome Research and Practice. 2007 Jul 9;12(1):55-9. Tajir F, Mahalakshmi K. Palatal bone thickness measured by palatal index method using cone-beam computed tomography in nonorthodontic patients for placement of mini-implants. Journal of pharmacy \& bioallied sciences. 2015 Apr;7(Suppl 1):S107.

13. Dhanapal, Suganya, Ravindra Kumar Jain, S. P. Dinesh, and S. Naveen Kumar. "Assessment of palatal depth and facial forms among adolescents in Chennai population-A prospective study." Drug Invention Today 11, no. 1 (2019).

14. Badshah M, Soames R, Khan MJ, Hasnain J. Morphology of the human hard palate: a study on dry skulls. Italian Journal of Anatomy and Embryology. 2018;123(1):55-63.

15. Maier CA, Adams DM. Standard Dimensions and Definitions for the Human Palate. Forensic Anthropology. 2018 Sep 22;1(4):215-21.

16. Bhagyalakshmi G, Renukarya A, Rajangam S. Metric analysis of the hard palate in children

17. Linder-Aronson S, Lindgren J. The skeletal and dental effects of rapid maxillary expansion. British Journal of Orthodontics. 1979 Jan;6(1):25-9.

18. Gwynne-Evans E. Discussion on the mouth-breather. Proceedings of the Royal Society of Medicine. 1958 Apr;51(4):279-82.

19. Klein ET. The thumb-sucking habit: Meaningful or empty?. American journal of orthodontics. 1971 Mar 1;59(3):283-9.

20. Cleall JF, Bayne DI, Posen JM, Subtelny JD. Expansion of the midpalatal suture in the monkey. The Angle Orthodontist. 1965 Jan;35(1):2335 .

21. Brossman RE, Bennett CG, Merow WW. Facioskeletal remodelling resulting from rapid palatal expansion in the monkey (Macaca cynomolgus). Archives of oral biology. 1973 Aug 1;18(8):987-IN3.

22. Handelman CS, Wang L, BeGole EA, Haas AJ. Nonsurgical rapid maxillary expansion in adults: report on 47 cases using the Haas expander. The Angle Orthodontist. 2000 Apr;70(2):129-44.

23. Ashley-Montagu MF. The form and dimensions of the palate in the newborn. International Journal of Orthodontia and Dentistry for Children. 1934 Aug 1;20(8):810-27.

24. Redman RS, Shapiro BL, Gorlin RJ. Measurement of normal and reportedly malformed palatal vaults. II. Normal juvenile measurements Journal of dental research. 1966 Mar;45(2):266-9. 